\title{
Article \\ Student Learning Approaches: Beyond Assessment Type to Feedback and Student Choice
}

\author{
Alice Clack and Eleanor J. Dommett*(D) \\ Department of Psychology, Institute of Psychiatry, Psychology and Neuroscience, King's College London, \\ London SE5 8AF, UK; alice.clack@kcl.ac.uk \\ * Correspondence: Eleanor.dommett@kcl.ac.uk; Tel.: +44-207-848-6928
}

Citation: Clack, A.; Dommett, E.J. Student Learning Approaches: Beyond Assessment Type to Feedback and Student Choice. Educ. Sci. 2021,

11, 468. https://doi.org/

10.3390/educsci11090468

Academic Editor: Mike Joy

Received: 16 July 2021

Accepted: 23 August 2021

Published: 26 August 2021

Publisher's Note: MDPI stays neutral with regard to jurisdictional claims in published maps and institutional affiliations.

Copyright: (c) 2021 by the authors. Licensee MDPI, Basel, Switzerland. This article is an open access article distributed under the terms and conditions of the Creative Commons Attribution (CC BY) license (https:// creativecommons.org/licenses/by/ $4.0 /)$.

\begin{abstract}
Student Approaches to Learning (SAL) have been the focus of much research, typically linking different approaches, e.g., surface and deep, to different assessment types. However, much of the previous research has not considered the different conditions under which different types of assessment occur and the different types of feedback they typically attract. In the current study, UK university students were allocated to one of two assessment conditions (Multiple Choice Questions (MCQs) or short essay). Half of the participants were then given the choice of receiving a grade or written feedback, whilst the other half were randomly allocated to one of the two feedback types. Participants were required to learn specific material and complete an assessment. Study time, assessment time, grade and notetaking approaches were analysed along with SAL, measured using the Study Process Questionnaire. Results indicated that participants performed better when they completed MCQs and expected to receive written feedback. There were no significant differences in feedback preferences between the two assessment types. There was no relationship between assessment, feedback type and SAL, however, interaction effects suggest that where students have a choice, those who choose written feedback exhibit deeper learning. This study is the first to demonstrate, albeit in an artificial learning activity, that the type of feedback students expect to receive may impact on their outcomes and the SAL in advance of receiving the feedback. Furthermore, the relationship between feedback and SAL may be moderated by student choice. Whilst further research is needed, this study indicates that the relationship between assessment, feedback and choice is complex.
\end{abstract}

Keywords: learning approaches; Study Process Questionnaire (SPQ); feedback; student choice

\section{Introduction}

Teaching practice within Higher Education (HE) has seen remarkably little change over long periods of time. Despite this, or perhaps because of it, there has been an increasing drive for evidence-based practice within the sector. This drive is likely caused by a range of factors including a need to justify public funding and to provide support for institutional policies and approaches [1], particularly in the face of increased student fees. One area which is now firmly embedded within the research narrative, having emerged in the 1970s [2], is student approaches to learning (SAL), which can be defined as the way students go about their learning in a specific situation [3]. These approaches may also be referred to as patterns of learning [4] or dispositions to learning [1] and are thought to be more flexible in HE students than in lower levels of education [5], which makes them particularly relevant to this educational sector. SAL can be distinguished from learning styles because they take into account the effects of previous experiences and contextual factors [6]. They can be conceptualized in a range of ways but are typically dichotomized into surface and deep approaches, with the former relying on rote learning and memorization and the latter requiring understanding of meaning and significance. Each approach incorporates a strategy and motive component, and whilst a student may 
tend to adopt one approach over another, they will be influenced by the situation or context [7]. Some researchers argue that deep learning is essential for success in HE because studying at this level requires knowledge synthesis that can only be obtained with this approach [8]. Moreover, it is suggested that this is now more important than ever before because societal functioning demands more than a basic knowledge and understanding of a domain of study [9]. Early studies supported the idea that success in HE was related to SAL by looking at the associations between SAL, study motivations, strategies and performance [10-12] with many, but not all, studies showing that deeper learning approaches were associated with better performance, a finding that continues to be supported in some later work [13]. Other studies looked beyond the individual student and started to explore the impact of the teaching environment on SAL and showed links between teaching strategy and SAL [14]. Research has also demonstrated associations between SAL and feedback, including mixed results regarding the impact of formative feedback [9] and the fact that students with different SAL may value differing components of written feedback [15]. It is within this rich research context that it was established that one of the most salient factors impacting on a student's choice of approach is the method of assessment $[16,17]$

\subsection{Student Approaches to Learning and Assessment}

Research into the relationship between SAL and assessment stems from the 'Backwash Effect' which, building on early research, recognizes that assessment can influence the SAL $[18,19]$. This research has focused almost exclusively on two specific types of assessment, which students often encounter in their studies: multiple choice question (MCQ) examinations and essay assignments [20]. Within this research, it is well-documented that students associate MCQ examinations with superficial cognitive processing and adopt a surface learning approach for these assessments [21-23], although this relationship may vary according to whether the MCQs are factual or applied [24], the academic ability of the students [22], the academic discipline and gender [20]. By contrast, research suggests that students believe that essay assignments require a higher level of cognitive processing and that these are associated with a deeper learning approach [25]. A key difference between the two types of assessment on which research has focused is that MCQs are typically completed under exam conditions, whilst essays are part of coursework assignments without time pressures, and this may have confounded previous research [20]. There is limited research into essays as part of examinations, but what does exist suggests a that if a relationship is found between specific approaches and assessment types, it is likely be to complex. For example, a relationship in which quantity and quality of answers may be differentially linked to a deep learning approach which impacts on the relationship between SAL and performance [26]. In addition to the varying conditions under which assessments are typically taken for MCQs and essays, a second factor that normally varies is the type of feedback received. Given that the provision of appropriate and timely feedback is thought to promote deep learning [27], this should be considered carefully. MCQ examinations are typically computer-marked and so feedback consists of a single grade, whilst essays may be accompanied by extensive written comments meaning that the differences in feedback could be as important as the assessment types they relate to.

\subsection{Student Feedback Preferences}

Feedback can be defined as information provided by an agent (e.g., teacher) regarding performance or understanding [28]. The provision of high-quality feedback is a key component of teaching and learning at all levels, including in HE [29], and it is thought to be one of the most influential (top 5-10) factors determining achievement [28] and a significant tool to enhance student abilities [30-32]. Indeed, it is an area of focus in several national metrics to assess teaching quality (e.g., National Student Satisfaction Survey, Teaching Excellence Framework). Despite the focus on feedback, delivering high quality feedback that can be acted on by students is a complex task [33], and students regularly complain that the feedback they receive is not useful or timely [34]. One of the challenges 
of feedback is ensuring that students have suitable feedback literacy to allow them to decode the feedback [35], which is likely to involve several processes including appreciating the feedback, making judgements and managing affect, all prior to taking action [33].

Even with strong interest in feedback, it is only relatively recently that student perceptions and preferences for feedback, rather than assessment, have been subject to scrutiny. Within the existing research there is clear evidence that students value feedback and understand its place in improved learning outcomes [27,36-38]. Perhaps unsurprisingly, there is a general preference for unambiguous feedback which was not overly negative [39], as well as feedback which is personalized [40]. In terms of specific comparisons between grade and written feedback, research has found that students preferred brief written comments, stating that written summaries were most useful [41]. Although the researchers found that there was still some value placed on just receiving a grade, written feedback was deemed desirable to help understand the grade received and how to improve it in the future. A recent qualitative study which actually required students to evaluate pieces of written feedback, rather than just reflect on their own experiences, found that features of highly valued feedback included receiving specific rather than general praise and feedback that was clear, error-free and forward-orientated [42]. In terms of academic performance, it has been shown that that students who received detailed feedback had the highest academic performance in their next essay compared to students that received just a grade or both a grade and praise [43]. Despite preferences for feedback approaches emerging from the literature, there is little linking between the type of assignment and preferred feedback-the two are often considered in isolation. It is likely that feedback preferences for MCQs, for example, differ from essays, although this has not previously been researched.

Alongside research into feedback preferences, there is also a burgeoning body of research linking feedback to SAL. For example, it has been suggested that the provision of appropriate and timely [27] or continuous [44] feedback can promote deep learning. However, others have found that additional feedback did not impact learning approach in student teachers and that formative feedback in undergraduate criminology students led students to take a more surface approach [45], a finding which may relate to perceived workload [9].

Given that the research into SAL and assessment types indicates that there is an impact of type of assessment on the approach students adopt when preparing for the assessment, and that there is research showing that feedback also relates to SAL, it is possible that SAL may be affected by the type of feedback expected, as well as whether that is the preferred type for that assignment. Irrespective of the exact relationship, a key concern is how students use feedback and how this may be impacted by SAL [46], making it important to explore further the relationship between assessment, feedback and SAL.

\subsection{The Present Study}

The over-arching aim of this study is to further explore how SAL relate to assessment. Specifically, we have four aims in the present study. Firstly, we seek to provide clarity on whether SAL differs for MCQ and short essay questions when both are completed under the same conditions, in this case, with a time restriction. Secondly, we aim to evaluate whether the type of feedback expected (grade or written) influences SAL. Thirdly, we will identify feedback preferences for MCQ and short essay questions. Finally, we will examine the effect of student choice of feedback on SAL.

\section{Materials and Methods}

\subsection{Participants}

The data for this study were collected from full-time undergraduate students studying at a single university in the UK. All participants were over 18 years old and could be studying in any academic discipline $(\mathrm{N}=63$, female $=52)$. A priori power calculations $(\alpha=0.05$, power $>0.8)$ were conducted to establish the required sample size using G-Power. Effect sizes for assessment type and feedback preferences been previously been found to be 
medium-large [25] and large, respectively [41]. There are no previous studies investigating student choice in a comparable way to the present study. Therefore, based on a large effect size, power calculations were carried out and indicated a total sample of 52 would be appropriate. Given the 8 groupings, we aimed to recruit 64 participants in total.

Recruitment was conducted via a fortnightly university e-newsletter and through poster advertisement across the campuses and residences. Participants interested in completing the study were asked to contact us via email, after which they were provided with further details of the study and their eligibility to participate was confirmed. Participants were excluded on the grounds of having a learning disability such as dyslexia because previous research indicates this can alter SAL [47]. Eligible participants were allocated a time slot to participate in the study, which took approximately $45 \mathrm{~min}$. Written informed consent was obtained from participants in person on arrival for testing. Ethical approval for the study was gained in advance from the Institutional Ethics Committee MRSU-19/20-14578. Participants received a GBP 7 Amazon voucher honorarium.

\subsection{Study Design}

This study used a $2 \times 2 \times 2$ factorial design with three between-participant independent variables or factors: Factor 1: Assessment Type (MCQ, short essay question); Factor 2: Feedback Choice (Choice, No Choice); Factor 3: Feedback Type (Grade, Written). Participants were randomized into conditions for Factor 1 and Factor 2 on arrival according to a pre-prepared spreadsheet using a Latin Square approach. Those in the 'No Choice' condition for Factor 2 were then further randomized into a Feedback Type condition. For each participant, several dependent variables were collected (as detailed in 'Procedure'): (a) Performance as a grade out of 10, (b) Learning time if completed before $15 \mathrm{~min}$, (c) Assessment time if completed before $15 \mathrm{~min}$, (d) SAL and (e) notetaking approach.

\subsection{Procedure}

All testing took place in the Psychology Department Test Laboratories which contained a single computer using the standard operating system of the university (i.e., one that students would be familiar with), a desk and chair for use by the participant and a separate desk and chair for the experimenter. On arrival for testing, participants were given a unique ID to enter the online data collection system (Gorilla, UK) after consent was obtained. Participants were first asked to answer three demographic questions (Gender, Age, Faculty or Academic Discipline). After completing these questions, on-screen and verbal instructions informed the participant that they had $15 \mathrm{~min}$ to watch a 6-min video entitled 'Why do we dream' (https:/ / youtu.be/7GGzc3 × 9WJU, accessed on 28 October 2019) and learn the material from the video for subsequent assessment. They were advised that they may pause the video at any time and replay the video if they wished, and they could use the pen and paper provided to make notes during this period, although these notes would be collected in prior to the assessment. We opted to use videoed teaching material to ensure that all participants received the exact same material delivered at the same pace and level. Furthermore, the use of video in learning is increasing significantly in HE, with tools such as lecture capture being used frequently by students, both in place of, and as well as, attending live lectures [48]. Participants in the Choice Condition were asked what type of feedback they would like to receive at this stage. When participants were ready to begin the learning period, they pressed 'Start' and the video would play. To help participants keep track of time, a timer displayed on the screen for the final two minutes. Participants could tell the experimenter if they thought they had learnt enough prior to using the full $15 \mathrm{~min}$, and the experimenter would note this time and progress to the next stage. Note that all participants knew what Assessment Type and Feedback Type they were going to receive prior to learning.

At the end of the learning period, all notes were collected and participants received further on-screen and verbal instructions explaining that they had a further $15 \mathrm{~min}$ to complete a short test. If they were completing MCQs, they were asked to select only one answer 
for each of the 10 questions, with each question worth one mark. If they were completing short essay questions, they were advised that they had to answer two questions worth 5 marks each where a portion of the marks was allocated to writing in appropriate academic style. When the participant indicated they were ready to begin, the experimenter provided the question sheet and began the 15-min timer. As with the learning period, if the participant felt they had completed their test to the best of their abilities prior to the end of the period, they could hand in their test sheet and the time at which this was done was recorded. A verbal two-minute warning was given for the end of the 15-min period. After completion of the assessment, the experimenter marked the assessment according to a pre-specified marking guidance and provided either a grade out of 10 or written feedback. The written feedback for MCQs related to content only (e.g., Excellent understanding of the content of the video), whilst the written feedback for short essay questions included comments on content (e.g., coherent description of the two views on why we dream and good level of detail, e.g., of two points about each view), style of writing (e.g., Mostly written in continuous prose but with some errors) and accuracy or quality of writing (e.g., Writing does not always flow logically, with some punctuation, grammar or spelling issues).

Finally, participants returned to the online data collection system to complete the revised two factor version of the Study Process Questionnaire (R-SPQ- 2F) considering their learning in the test session. This 20-item scale includes 10 items measuring a deep approach (e.g., 'I find most new topics interesting and often spend extra time trying to obtain more information about them') and 10 measuring a surface approach ('I find I can get by in most assessments by memorizing key sections rather than trying to understand them.) ( 1 = never or only rarely true of me, 5 = always or almost always true of me) [49]. A range of different conceptual frameworks and measures (mostly self-report) are available for measuring SAL, with a recent systematic review showing that the most commonly used is Biggs' Study Process Questionnaire, followed by Entwistle's framework [50]. Interestingly, consistency of findings between studies is lacking even where the same conceptual framework has been used. One possible reason for this is the breadth of the context studied. Early studies (e.g., [16]) focused on SAL within specific tasks whilst much of the later research has consider SAL over longer period [50] even though it is generally accepted that approaches to learning are context specific [51,52]. Furthermore, different measurement instruments were designed to employed at different levels of context as well. In the present study, which could be described as a task or course, rather than general SAL across activities, we opted to use the Study Process Questionnaire (R-SPQ-2F) because it has been used in much of the previous research allowing for comparison and, most importantly, it was designed to measure at course level [3].

\subsection{Data Processing}

Demographic data was used only to characterize the sample. The only processing required here was to allocate students to one of two areas based on their discipline (a) health/science-related or (b) non-health/science-related. Whilst this may seem to be an over-simplification, a similar structure exists within the university, and therefore this is a logical approach for this context.

The grade- and time-dependent variables were either calculated as indicated above or noted down during the procedure and required no further processing before analysis. The R-SPQ- 2F scale scores were combined to give specific scores. Ten items were summed to provide an overall measure of Deep Learning (DL, $\alpha=0.66$ ), and the remaining ten have a measure of Surface Learning (SL, $\alpha=0.76)$. Subscale scores were also calculated for Deep Strategy (DS, $\alpha=0.55)$, Deep Motive (DM, $\alpha=0.54)$, Surface Motive (SM, $\alpha=0.77$ ) and Surface Strategy (SS, $\alpha=0.68$ ). The internal reliability scores (Cronbach's alpha) were deemed minimally acceptable if they fell within the 0.65 and 0.70 range and were considered respectable if they fell between 0.70 and 0.80 [33]. The overall DL and SL were therefore considered to be reliable, as were the scores for SM and SS. The scores for DM and DS fell short of this, but these scores were lower in the original scale development 
work [32] and the inter-item correlations met the optimal level (0.2 to 0.4$)$, indicating that these scales are acceptable [34,35].

For the notetaking analysis, a content analysis was adapted from a previous study exploring notetaking in students, which examined notes according to criteria including volume of notes, use of diagrams and complexity of notes, e.g., linear structure as simple vs. embedded structure and conceptual links for complex [36]. Using these criteria, ratings were given to each set of notes corresponding to Low (1), Medium (2) and High (3).

\section{Results}

\subsection{Sample Characterisation and Feedback Preferences}

Sixty-three participants took part in the study and the majority were female $(\mathrm{N}=52$, $83 \%)$. The overall student population at this university is female-dominated (66\%), although the participant sample may have still over-represented females. However, chisquare analysis showed that there were no significant gender differences in the conditions for each of the three factors (Assessment type: $\chi^{2}(1)=1.110, p=0.292$; Feedback type: $\chi^{2}(1)=0.256, p=0.613$; Student choice: $\left.\chi^{2}(1)=0.879, p=0.348\right)$. The mean $(S D)$ age of participants was 19.95 (2.05) years as may be expected for a student population, and this did not differ according to the conditions of the three factors as assessed by independent sample $\mathrm{t}$-tests (Assessment type: $\mathrm{t}(61)=1.008, p=0.317$; Feedback type: $\mathrm{t}(61)=0.944$, $p=0.195$; Student choice: $\mathrm{t}(61)=0.534, p=0.595)$. In terms of discipline, the majority fell into health/science-related disciplines ( $\mathrm{N}=48,76 \%)$. This is perhaps not surprising given that the university includes a very large medical school. In any event, the chi-square analysis revealed that there were no significant discipline differences in the conditions for each factor (Assessment type: $\chi^{2}(1)=0.134, p=0.714$; Feedback type: $\chi^{2}(1)=0.007$, $p=0.933$; Student choice: $\chi^{2}(1)=2.401, p=0.121$ ).

Table 1 provides a summary of the participants in the different conditions of the three independent variables or factors. This table indicates that where choice was permitted in feedback, 7/15 participants selected written feedback for MCQs in contrast to 8/15 requiring just a grade, indicating no real preference for either type of feedback in this type of assessment. By contrast, for short essay questions, the majority $(11 / 16)$ requested written feedback, indicating a stronger preference. However, chi-square analysis showed no significant difference in preferences between the two types of assessment $\left(\chi^{2}(1)=2.03\right.$, $p=0.285)$.

Table 1. Sample sizes in the different conditions.

\begin{tabular}{ccc}
\hline Assessment Type (N) & Feedback Choice (N) & Feedback Type (N) \\
\hline MCQ (31) & Yes (15) & Written (7) \\
& & Grade (8) \\
& No (16) & Written (8) \\
& & Grade (8) \\
Short essay (32) & Yes (16) & Written (11) \\
& & Grade (5) \\
& No (16) & Written (8) \\
& & Grade (8) \\
\hline
\end{tabular}

Table 2 provides an overview of the notetaking approaches taken by participants in this study and suggests a range of approaches was found. How these relate to outcomes and SAL is considered in the next section. 
Table 2. Notetaking categorization for participants. Numbers indicate participants taking specific approach.

\begin{tabular}{cccc}
\hline & Low & Moderate & High \\
\hline Volume of notes & 31 & 26 & 6 \\
Use of diagrams & 57 & 6 & 0 \\
Level of detail & 35 & 24 & 4 \\
\hline
\end{tabular}

\subsection{Outcome Measures}

Although the main aim of the study was to examine the impact of changes in assessment and feedback on SAL, we also collected data on performance and time taken for learning and assessment and therefore conducted analyses on these. A univariate ANOVA with grade as the dependent variable revealed significant main effects. Firstly, there was a significant main effect of Assessment Type $(\mathrm{F}(1,55)=4.0, p=0.05)$, with higher grades in the MCQ $(\mathrm{M}=8.94, \mathrm{SD}=1.24)$ than the short essay questions $(\mathrm{M}=8.41$, $\mathrm{SD}=1.29)$ (Figure 1A). Secondly, there was a significant main effect of Feedback Type $(\mathrm{F}(1,55)=7.21, p=0.01)$, with those expecting to receive written feedback $(\mathrm{M}=9.00$, $\mathrm{SD}=1.06)$ outperforming those who expected to receive a grade $(\mathrm{M}=8.30, \mathrm{SD}=1.42)$ (Figure 1B). There was no significant effect of Feedback Choice $(\mathrm{F}(1,55)=0.189, p=0.665)$. There were no significant interactions.
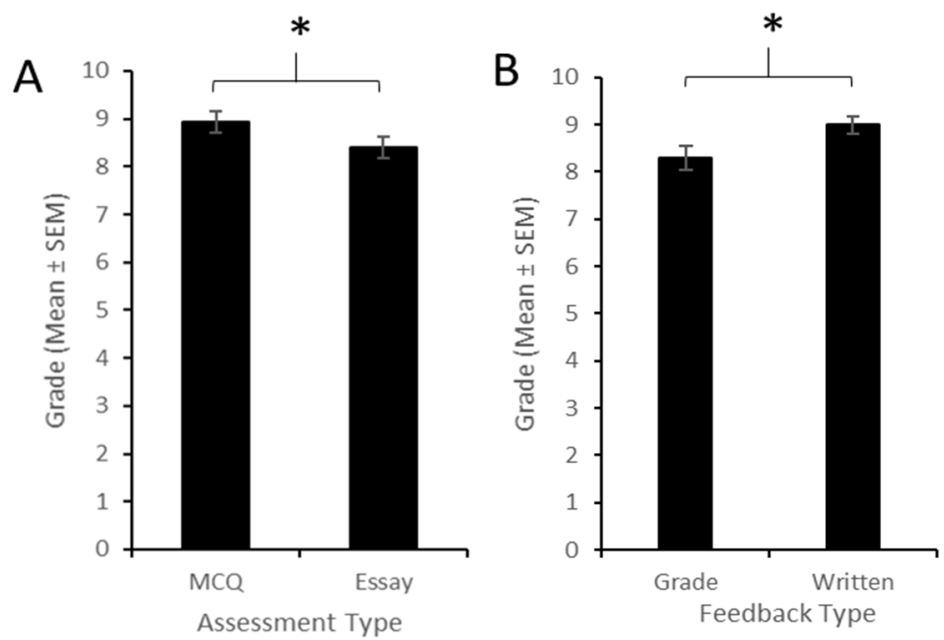

Figure 1. There were significant differences between the grade achieved according to both Assessment Type (A) and Feedback Type (B). ${ }^{*} p<0.05$.

A univariate analysis of the study time revealed no significant main effects, but there was a single significant interaction: Assessment Type $x$ Feedback Type $x$ Feedback Choice $(F(1,55)=5.27), p=0.026)$. Figure 2 indicates that the opposite pattern is found when there is choice over feedback in contrast to when there is not. However, restricted ANOVAs, restricting by choice, assessment type and feedback type, indicate that there are no significant two-way interactions, meaning that no firm conclusions can be made about this complex effect. Finally, a univariate analysis of assessment time revealed a significant main effect of Assessment Type $(\mathrm{F}(1,55)=190.28, p<0.001)$ with MCQs $(\mathrm{M}=2.07 \mathrm{~min}, \mathrm{SD}=0.86)$ being completed much quicker than short essay questions $(\mathrm{M}=9.70 \mathrm{~min}, \mathrm{SD}=2.80)$, as might be expected. There were no other significant main effects or interactions. 

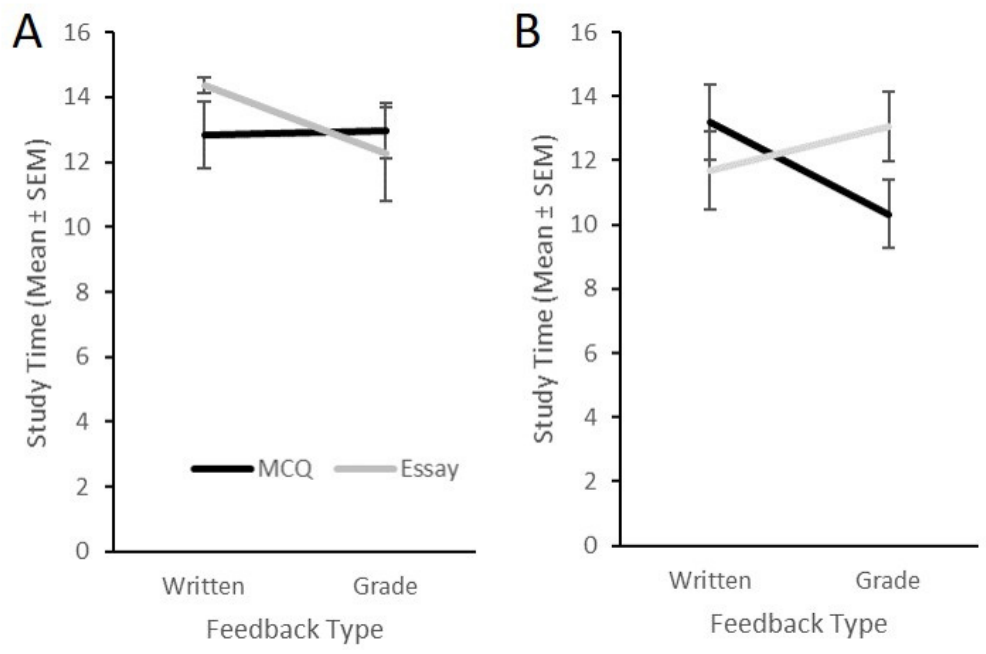

Figure 2. There was a significant Assessment Type $x$ Feedback Type $x$ Choice interaction. The exact basis of this is unclear, but opposite patterns are found for the Assessment Type $x$ Feedback Type interactions when participants are separated into those with Choice (A) versus No Choice (B).

To check for any relationship between SAL and outcome measures, we conducted a correlation analysis for the six measures from the R-SPQ- 2F (DL, SL, DS, DM, SS, SM) and grade, study time and assessment time (Table 3). As might be expected, there was a significant positive correlation between study time and grade. Similarly, there were significant correlations between the items with the R-SPQ-2F, as would be expected, i.e., significant positive correlations between measures of the same kind and negative correlations between opposing measures (i.e., deep vs. surface). There were no significant correlations between any SAL and outcome measure. We also examined whether the type of notes made impacted on grade and times taken, because it might be expected that higher level notes are indicative of a deeper approach. One-way ANOVAs revealed no effect of volume of notes, use of diagrams or complexity of notes on any of the measures (Volume: Grade F (2) $=0.225, p=0.799$, Study time F $(2)=0.145, p=0.866$, Assessment time F (2) $=0.399, p=0.672$; Detail: Grade F (2) $=0.175, p=0.902$, Study time F (2) $=0.000$, $p=1.000$, Assessment time F (2) $=0.091, p=0.913$; Diagram use: Grade F $(1)=1.815$, $p=0.183$, Study time F (1) $=0.040, p=0.841$, Assessment time F $(1)=0.086, p=0.770$ ). Finally, we examined the relationship between the SAL measures and the notetaking, using multivariate analysis. No significant differences in any of the SAL measures were found for the different classifications of the volume or complexity of notetaking $(p>0.05)$. However, there was a significant difference for diagram use and DS $(F(1,56)=4.00$, $p=0.05)$, with moderate use of diagrams associated with a higher DS score $(\mathrm{M}=17.50$, $\mathrm{SD}=1.22)$ compared to those making low use of diagrams $(\mathrm{M}=14.32, \mathrm{SD}=3.52)$.

Table 3. Correlation between outcome measures and R-SPQ-2F measures ${ }^{*} p<0.05,{ }^{* *} p<0.01$.

\begin{tabular}{|c|c|c|c|c|c|c|c|c|c|c|}
\hline & Scale Range & Mean (SD) & 1 & 2 & 3 & 4 & 5 & 6 & 7 & 8 \\
\hline 1. Grade & $1-10$ & $8.67(1.28)$ & & & & & & & & \\
\hline 2. Study Time & $0-15$ & $12.67(2.84)$ & $0.296^{*}$ & & & & & & & \\
\hline 3.Assessment Time & $0-15$ & $5.96(4.37)$ & -0.162 & 0.160 & & & & & & \\
\hline 4. Deep Learning & $10-50$ & $29.87(5.80)$ & 0.025 & 0.050 & -0.141 & & & & & \\
\hline 5. Surface Learning & $10-50$ & $25.25(7.22)$ & -0.061 & -0.126 & -0.054 & $-0.603^{* *}$ & & & & \\
\hline 6. Deep Motive & $5-25$ & 15.25 (3.47) & 0.045 & 0.037 & -0.106 & $0.832 * *$ & $-0.583 * *$ & & & \\
\hline 7. Deep Strategy & $5-25$ & $14.62(3.49)$ & 0.004 & 0.045 & -0.129 & $0.835^{* *}$ & $-0.567 * *$ & $0.390 * *$ & & \\
\hline 8. Surface Motive & $5-25$ & $12.05(4.58)$ & -0.019 & -0.154 & -0.041 & $-0.555^{* *}$ & $0.828^{* *}$ & $0.578^{* *}$ & $-0.348^{* *}$ & \\
\hline 9. Surface Strategy & $5-25$ & $13.84(4.29)$ & -0.124 & 0.049 & -0.047 & $-0.423^{* *}$ & $0.801 * *$ & $-0.415^{* *}$ & $-0.415^{* *}$ & $0.327^{* *}$ \\
\hline
\end{tabular}




\subsection{Student Learning Approach: Assessment, Feedback and Choice}

The main aim of the present study was to establish how SAL relates to assessment and feedback type, including when choice of feedback is permitted. To answer this question, we used a multivariate analysis with the six R-SPQ-2F as dependent variables and our three independent variables (Assessment Type, Feedback Type, Choice) as fixed factors. There were no significant main effects of any factors on any of the SAL measures (Supplementary Table S1). There was one significant interaction for Feedback x Choice for Deep Strategy $(F(1,55)=5.469, p=0.023$, Figure 3). Independent sample t-tests revealed no significant difference in Deep Strategy between those with choice and without when participants received grade feedback $(t(28)=0.61, p=0.550)$. However, there was a significant difference between choice groups when written feedback was received $(t(31)=2.92, p=0.007)$, with those in the Choice group having a deeper strategy $(\mathrm{M}=15.89, \mathrm{SD}=3.08)$ than those in the No Choice group $(\mathrm{M}=12.53$, $\mathrm{SD}=3.52)$. This result indicates that when students can select the type of feedback they receive, those selecting written feedback take a deeper approach.

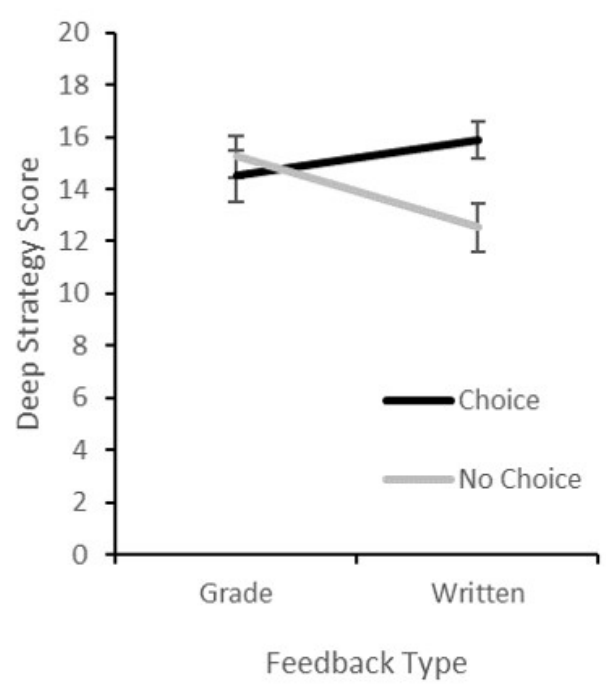

Figure 3. There was no difference in deep learning strategy for participants with no choice. However, where choice over Feedback Type was given, those selective written feedback showed a deeper strategy.

\section{Discussion}

\subsection{The Relationship between Assessment Type and Learning Approach}

The first aim of this study was to provide clarity on whether SAL differs for MCQ and short essay questions when both are completed under the same conditions, in this case with a time restriction. The results of this study suggest that there is no difference in the SAL between these two assessment types when they are both completed in the same conditions. This indicates that previous studies may have been, at least in part, confounded by the different conditions under which these assessments are typically completed [20]. The results of the present study are in line with some previous research $[20,22]$ despite many findings showing, for example, that MCQs are associated with a surface approach $[21,23,25]$. Although not unprecedented, it is still helpful to consider why we did not find a relationship between the SAL and assessment type. One possibility is that it is not the nature of the assessment that determines the SAL but rather the conditions, meaning that whilst an essay under coursework conditions may encourage a deeper approach, one under exam conditions simply does not. Secondly, it is possible that the nature of the assessment contributes to the learning approach adopted but that it is not the only impacting factor, such that effects may not always been seen. Certainly, evidence suggests that factors such as student intention, motivation and self-regulation may also be important [18], all of which may be impacted by the artificial nature of the task in the current study. Thirdly, the artificial 
nature of the task here may have meant that students did not have enough information and study time to take a deep approach to their learning even if they wanted to, irrespective of the assessment type. Based on the total surface and deep scores in the present study being similar, this is plausible. Given the nature of the study, which rather than being hypothetical required students to learn new information in the testing period, the amount covered was small. Although deep learning does not necessarily require large amounts of learning, the features of deep learning, such as synthesis of ideas, may mean that it was not plausible in the current study.

\subsection{Feedback Preferences and the Impact of Expected Feedback on Learning Approach}

The remaining aims of the study were to evaluate whether the type of feedback expected (grade or written) influences SAL, identify feedback preferences for MCQs and short essay questions and examining the effect of student choice of feedback on SAL. The present study demonstrated no impact of expected feedback on SAL, although participants performed better when they expected written feedback. A positive relationship between good feedback and outcome has been previously reported [43,53], however, in previous studies, the feedback has been used to improve the performance. By contrast, in the present study, this was prospective, i.e., they knew which feedback to expect rather than having benefitted from the feedback. One possibility is that students simply made more effort when they thought they would receive written feedback because they perceive this to be a higher quality of feedback [41]. Certainly previous work has demonstrated a significant positive correlation between quality of feedback and student effort [54]. However, if more effort had been made, we might have expected to see this in the SAL measures or changes in the note-taking strategies, which was not the case. We did, however, find a significant Choice $x$ Feedback interaction for deep strategy, which suggested that when students can select the type of feedback they receive, those selecting written feedback did take a deeper approach. The basis for this finding is unclear, but there may be several explanations for it. Firstly, students could be playing the 'examination game' in which they consider factors such as how something will be marked before they study for it and conclude that written feedback will require greater depth [55]. However, if this were the case, we would expect to find a main effect of feedback type on SAL which we did not. Secondly, the act of asking for written feedback could help foster deep learning; research has found that students report that learning how to ask for feedback (but not a grade) can help them focus on a deeper approach [56]. One way to examine this would have been to ask a subset of students to select their choice only after they have learnt the material, not before, as we did in the present study.

We also found no significant differences in feedback preferences for the two types of assessment, although twice as many students opted for written feedback as opposed to a grade on the essay questions. The lack of significance here could result from a lack of statistical power. However, it may also be because they were not required to act on the feedback given, that is, the artificial design meant they would not have to continue learning this material or build on the work with further assessment. Future research should consider exploring why students make specific choices about feedback, rather than just asking them to make a choice. Finally, we did not find a significant main effect of choice on any of the measures related to SAL. We did, as discussed above, find a significant interaction with feedback type for deep strategy. These results suggest that student choice may impact on learning approach, warranting further investigation. This is particularly pertinent given the emphasis on student choice in the sector in recent years, which has resulted in a drive towards a wider curriculum which allows for greater student choice $[57,58]$, including choice over assessment format [59]. 


\subsection{Evaluation of the Present Study and Future Research}

The current research took an innovative approach of creating a learning and assessment opportunity with novel information rather than asking students to report on previous experiences or comment on hypothetical approaches and feedback. This allowed us to employ a robust factorial design to address the study aims. Furthermore, the aims of the research were novel, seeking to address gaps in the literature surrounding the impact of feedback type and student choices whilst building on existing research into assessment types. In addition, by ensuring comparable content and conditions for the different types of assessment, we also overcame possible confounding variables in this type of research [20]. The inclusion of participants from all faculties was a strength of the design because much of the previous research tends to focus solely on scientific disciplines [60,61]. However, it must be noted that even in the present study, the majority of students still came from health related faculties, and the sample sizes meant that we could not differentiate between discipline effects, which may be important [20]. Furthermore, given that learning approaches are context dependent, the use of a specific task may have impacted the approach taken and a range of tasks should be considered in future. Finally, the use of videoed teaching material in the present study could be considered a strength given the increased reliance on tools such as lecture capture and students highly positive perceptions of these tools, meaning that many students consider videoed lectures a key learning resource [48]. Moreover, the rapid switch to online learning in response to the COVID-19 pandemic means that the use of video makes this all the more relevant to the current HE context.

Despite the strengths in the design of this study, there are some limitations. For example, whilst the sample size exceeded the total sample calculated to identify large effect sizes, which may be expected for assessment and feedback preference, it was slightly smaller than we aimed for (63 rather than 64) and may not be sufficiently powered to detect smaller effect sizes. This is particularly pertinent for Student Choice where there is no suitable research to glean effect sizes from. Therefore, future studies should consider powering for smaller effect sizes. Additionally, the sample was biased towards females. Although the university where data collection occurred does have more females than males, this difference is not as large as in the sample for the present study, meaning results may not generalize to other populations.

Furthermore, although our design meant that we did not have to rely on retrospective or hypothetical analysis of feedback and approaches, it was still a simulated learning experience which participants self-selected to participate in and which was conducted over a limited period of time (the equivalent of one lesson) and, as such, it is possible that findings may not generalize to real-world assessment that carries weighting in a student's degree result. For example, the impact of feedback is known to be dependent on student feedback literacy with the most useful feedback considered to be fluid and interactive [30], and the process of improvement is dependent on students active and ongoing engagement with feedback [62], which was not the case here. Future research should be conducted within real learning situations. A further weakness in the study may arise from how participants were able to interact with the learning material. Although the use of video could be considered a strength, it also did not allow for dialogue with the teacher. Additionally, students could not skip the video or move forwards or backwards, but they could pause it and replay it in its entirety, which most participants did. This limited interaction could have affected the way the participant learned the content of the video and may not be representative of how they study in general for real examinations or assessments. Future research should consider how to test these factors, in a real-life learning situation. Finally, this study used the study process questionnaire to examine learning approaches, which carries with it some limitations. Whilst the reliability of the R-SPQ-2F in the present study aligned with its original development, arguably the DS and DM scores were not reliable, meaning that the results for these scales should be interpreted with caution. This is unlikely to be due to the relatively small sample size because research suggests a minimum sample of 50 to obtain appropriate alpha values [63]. Furthermore, alpha is only one measure 
of reliability and inter-item correlation did show acceptable levels here. Despite this, future studies should consider whether alternative instruments might be used if alpha does not meet minimal acceptable levels. Additionally, this instrument, whilst commonly used and suited for the context chosen, is only one way of measuring SAL and assumes a dichotomous view of learning (i.e., surface or deep). However, other conceptualizations and instruments could give different findings. For example, the learning patterns model assumes greater complexity and identifies three main processing strategies (deep, stepwise and concrete) [4]. It should also be noted that we only measured SAL and not other factors known to be related to this such as organisation and motivation [18].

Acknowledging the strengths and limitations of the current study, it can be concluded that this study is the first to demonstrate, albeit in an artificial learning activity, that the type of feedback that students expect to receive may impact on their outcomes and the SAL in advance of receiving the feedback. Furthermore, the relationship between feedback and SAL may be moderated by student choice. Whilst further research is needed to replicate and extend these findings to a broader population, this study indicates that the relationship between assessment, feedback and choice is complex. Given that one of the core aims of HE remains to promote deep learning, this research suggests extending the tool kit available to teachers to promote this approach, beyond type of assessment and provision of quality feedback to include student choice of feedback.

Supplementary Materials: The following are available online at https:/ / www.mdpi.com/article/10.3 390/educsci11090468/s1, Table S1: Analyses of the effects of Assessment, Feedback, and Choice on SAL.

Author Contributions: Conceptualization, A.C. and E.J.D.; Data collection, A.C.; Data Analysis, A.C. and E.J.D.; Writing - review and editing, E.J.D. All authors have read and agreed to the published version of the manuscript.

Funding: This research received no external funding.

Institutional Review Board Statement: The study was conducted according to the guidelines of the Declaration of Helsinki, and approved by the Institutional Review Board (or Ethics Committee) of King's College London (Reference MRSU-19/20-14578 and date of approval 08.10.19).

Informed Consent Statement: Informed consent was obtained from all subjects involved in the study.

Data Availability Statement: Data is available on reasonable request from the corresponding author.

Conflicts of Interest: The authors declare no conflict of interest.

\section{References}

1. Entwistle, N.; McCune, V. The conceptual bases of study strategy inventories. Educ. Psychol. Rev. 2004, 16, 325-345. [CrossRef]

2. Beattie, V., IV; Collins, B.; McInnes, B. Deep and surface learning: A simple or simplistic dichotomy? J. Account. Educ. 1997, 6, 1-12. [CrossRef]

3. Biggs, J.B. Student Approaches to Learning and Studying; Council for Educational Research: Hawthorn, VIC, Australia, 1987.

4. Vermunt, J.D.; Donche, V. A learning patterns perspective on student learning in higher education: State of the art and moving forward. Educ. Psychol. Rev. 2017, 29, 269-299. [CrossRef]

5. Song, Y.; Vermunt, J.D. A comparative study of learning patterns of secondary school, high school and college students. Stud. Educ. Eval. 2021, 68, 100958. [CrossRef]

6. Coffield, F.; Moseley, D.; Hall, E.; Ecclestone, K.; Coffield, F.; Moseley, D.; Hall, E.; Ecclestone, K. Learning Styles and Pedagogy in Post-16 Learning: A Systematic and Critical Review; Learning \& Skills Research Centre: London, UK, 2004.

7. Baeten, M.; Kyndt, E.; Struyven, K.; Dochy, F. Using student-centred learning environments to stimulate deep approaches to learning: Factors encouraging or discouraging their effectiveness. Educ. Res. Rev. 2010, 5, 243-260. [CrossRef]

8. Chotitham, S.; Wongwanich, S.; Wiratchai, N. Deep learning and its effects on achievement. Procedia Soc. Behav. Sci. 2014, 116, 3313-3316. [CrossRef]

9. Gijbels, D.; Dochy, F. Students' assessment preferences and approaches to learning: Can formative assessment make a difference? Educ. Stud. 2006, 32, 399-409. [CrossRef]

10. Biggs, J.B. Individual differences in study processes and the quality of learning outcomes. High. Educ. 1979, 8, 381-394. [CrossRef]

11. Biggs, J.B. Faculty patterns in study behaviour. Aust. J. Psychol. 1970, 22, 161-174. [CrossRef]

12. Entwistle, N.J.; Entwistle, D. The relationships between personality, study methods and academic performance. Br. J. Educ. Psychol. 1970, 40, 132-143. [CrossRef] 
13. Phan, H.P. Relations between goals, self-efficacy, critical thinking and deep processing strategies: A path analysis. Educ. Psychol. 2009, 29, 777-799. [CrossRef]

14. Hall, M.; Ramsay, A.; Raven, J. Changing the learning environment to promote deep learning approaches in first-year accounting students. J. Account. Educ. 2004, 13, 489-505. [CrossRef]

15. Winstone, N.E.; Nash, R.A.; Rowntree, J.; Menezes, R. What do students want most from written feedback information? Distinguishing necessities from luxuries using a budgeting methodology. Assess. Eval. High. Educ. 2016, 41, 1237-1253. [CrossRef]

16. Marton, F.; Säaljö, R. On qualitative differences in learning-Ii Outcome as a function of the learner's conception of the task. Br. J. Educ. Psychol. 1976, 46, 115-127. [CrossRef]

17. Trigwell, K.; Prosser, M. Improving the quality of student learning: The influence of learning context and student approaches to learning on learning outcomes. High. Educ. 1991, 22, 251-266. [CrossRef]

18. Asikainen, H.; Parpala, A.; Virtanen, V.; Lindblom-Ylänne, S. The relationship between student learning process, study success and the nature of assessment: A qualitative study. Stud. Educ. Eval. 2013, 39, 211-217. [CrossRef]

19. Biggs, J. Enhancing teaching through constructive alignment. High. Educ. 1996, 32, 347-364. [CrossRef]

20. Smith, S.N.; Miller, R.J. Learning approaches: Examination type, discipline of study, and gender. Educ. Psychol. 2005, 25, 43-53. [CrossRef]

21. Newble, D.I.; Jaeger, K. The effect of assessments and examinations on the learning of medical students. Med. Educ. 1983, 17, 165-171. [CrossRef] [PubMed]

22. Scouller, K.M.; Prosser, M. Students' experiences in studying for multiple choice question examinations. Stud. Educ. Eval. 1994, 19, 267-279. [CrossRef]

23. Thomas, P.; Bain, J. Contextual dependence of learning approaches. Hum. Learn. 1984, 3, 230-242.

24. Yonker, J.E. The relationship of deep and surface study approaches on factual and applied test-bank multiple-choice question performance. Assess. Eval. High. Educ. 2011, 36, 673-686. [CrossRef]

25. Scouller, K. The influence of assessment method on students' learning approaches: Multiple choice question examination versus assignment essay. High. Educ. 1998, 35, 453-472. [CrossRef]

26. Minbashian, A.; Huon, G.F.; Bird, K.D. Approaches to studying and academic performance in short-essay exams. High. Educ. 2004, 47, 161-176. [CrossRef]

27. Rowe, A.D.; Wood, L.N. Student perceptions and preferences for feedback. Asian Soc. Sci. 2008, 4, 78-88.

28. Hattie, J.; Timperley, H. The power of feedback. Rev. Educ. Res. 2007, 77, 81-112. [CrossRef]

29. Ramsden, P. Learning to Teach in Higher Education; Routledge: New York, NY, USA, 2003.

30. Carless, D. From teacher transmission of information to student feedback literacy: Activating the learner role in feedback processes. Act. Learn. High. Educ. 2020, 1469787420945845. [CrossRef]

31. Kluger, A.N.; DeNisi, A. The effects of feedback interventions on performance: A historical review, a meta-analysis, and a preliminary feedback intervention theory. Psychol. Bull. 1996, 119, 254. [CrossRef]

32. Wisniewski, B.; Zierer, K.; Hattie, J. The power of feedback revisited: A meta-analysis of educational feedback research. Front. Psychol. 2020, 10, 3087. [CrossRef]

33. Carless, D.; Boud, D. The development of student feedback literacy: Enabling uptake of feedback. Assess. Eval. High. Educ. 2018, 43, 1315-1325. [CrossRef]

34. Forsythe, A.; Johnson, S. Thanks, but no-thanks for the feedback. Assess. Eval. High. Educ. 2017, 42, 850-859. [CrossRef]

35. Sadler, D.R. Beyond feedback: Developing student capability in complex appraisal. Assess. Eval. High. Educ. 2010, 35, 535-550. [CrossRef]

36. Higgins, R.; Hartley, P.; Skelton, A. The conscientious consumer: Reconsidering the role of assessment feedback in student learning. Stud. Educ. Eval. 2002, 27, 53-64. [CrossRef]

37. Hyland, F. ESL writers and feedback: Giving more autonomy to students. Lang. Teach. Res. 2000, 4, 33-54. [CrossRef]

38. Weaver, M.R. Do students value feedback? Student perceptions of tutors' written responses. Assess. Eval. High. Educ. 2006, 31, 379-394. [CrossRef]

39. Price, M.; Handley, K.; Millar, J.; O'donovan, B. Feedback: All that effort, but what is the effect? Assess. Eval. High. Educ. 2010, 35, 277-289. [CrossRef]

40. Mulliner, E.; Tucker, M. Feedback on feedback practice: Perceptions of students and academics. Assess. Eval. High. Educ. 2017, 42, 266-288. [CrossRef]

41. Ferguson, P. Student perceptions of quality feedback in teacher education. Assess. Eval. High. Educ. 2011, 36, 51-62. [CrossRef]

42. Austen, L.; Malone, C. What students' want in written feedback: Praise, clarity and precise individual commentary. Pract. Res. High. Educ. 2018, 11, 47-58.

43. Lipnevich, A.A.; Smith, J.K. Response to assessment feedback: The effects of grades, praise, and source of information. ETS Res. Rep. Ser. 2008, 2008, i-57. [CrossRef]

44. Almeida, P.A.; Teixeira-Dias, J.J.; Martinho, M.; Balasooriya, C.D. The interplay between students' perceptions of context and approaches to learning. Res. Pap. Educ. 2011, 26, 149-169. [CrossRef]

45. Gijbels, D.; Coertjens, L.; Vanthournout, G.; Struyf, E.; Van Petegem, P. Changing students' approaches to learning: A two-year study within a university teacher training course. Educ. Stud. 2009, 35, 503-513. [CrossRef] 
46. Evans, C.; Cools, E.; Charlesworth, Z.M. Learning in higher education-how cognitive and learning styles matter. Teach. High. Educ. 2010, 15, 467-478. [CrossRef]

47. Polychroni, F.; Koukoura, K.; Anagnostou, I. Academic self-concept, reading attitudes and approaches to learning of children with dyslexia: Do they differ from their peers? Eur. J. Spec. Needs Educ. 2006, 21, 415-430. [CrossRef]

48. Dommett, E.J.; Gardner, B.; van Tilburg, W. Staff and students perception of lecture capture. Internet High. Educ. 2020, 46, 100732. [CrossRef]

49. Biggs, J.; Kember, D.; Leung, D.Y. The revised two-factor study process questionnaire: R-SPQ-2F. Br. J. Educ. Psychol. 2001, 71, 133-149. [CrossRef]

50. Asikainen, H.; Gijbels, D. Do students develop towards more deep approaches to learning during studies? A systematic review on the development of students' deep and surface approaches to learning in higher education. Educ. Psychol. Rev. 2017, 29, 205-234. [CrossRef]

51. Biggs, J.B. Teaching for Quality Learning at University: What the Student Does; McGraw-Hill Education (UK): London, UK, 2011.

52. Entwistle, N.; Ramsden, P. Understanding Student Learning (Routledge Revivals); Routledge: London, UK, 2015.

53. Bitchener, J. Evidence in support of written corrective feedback. J. Second Lang. Writ. 2008, 17, 102-118. [CrossRef]

54. Wu, Q.; Jessop, T. Formative assessment: Missing in action in both research-intensive and teaching focused universities? Assess. Eval. High. Educ. 2018, 43, 1019-1031. [CrossRef]

55. Entwistle, N.J.; Entwistle, A. Contrasting forms of understanding for degree examinations: The student experience and its implications. High. Educ. 1991, 22, 205-227. [CrossRef]

56. Filius, R.M.; de Kleijn, R.A.; Uijl, S.G.; Prins, F.; van Rijen, H.V.; Grobbee, D.E. Promoting deep learning through online feedback in SPOCs. Frontline Learn. Res. 2018, 6, 92. [CrossRef]

57. Smith, J. Learning styles: Fashion fad or lever for change? The application of learning style theory to inclusive curriculum delivery. Innov. Educ. Teach. Int. 2002, 39, 63-70. [CrossRef]

58. Knight, P.T. Complexity and curriculum: A process approach to curriculum-making. Teach. High. Educ. 2001, 6, 369-381. [CrossRef]

59. Irwin, B.; Hepplestone, S. Examining increased flexibility in assessment formats. Assess. Eval High. Educ. 2012, 37, 773-785. [CrossRef]

60. Reid, W.A.; Duvall, E.; Evans, P. Relationship between assessment results and approaches to learning and studying in year two medical students. Med. Educ. 2007, 41, 754-762. [CrossRef]

61. Leung, S.F.; Mok, E.; Wong, D. The impact of assessment methods on the learning of nursing students. Nurse Educ. Today 2008, 28, 711-719. [CrossRef]

62. Carless, D. Feedback loops and the longer-term: Towards feedback spirals. Assess. Eval. High. Educ. 2019, 44, 705-714. [CrossRef]

63. Javali, S.B.; Gudaganavar, N.V.; Raj, S.M. Effect of varying sample size in estimation of coefficients of internal consistency. Webmed Central 2011, 2, 1-15. 